\title{
Ultrasonography screening of carotid arteries in asymptomatic patients
}

\author{
Ivan N. Shchanitsyn ${ }^{1}$, Elena Yu. Shvarts ${ }^{1}$, Regina A. Ishmukhametova ${ }^{1}$, Aina S. Vozdeyeva ${ }^{1}$ \\ ${ }^{1}$ Saratov State Medical University, Saratov, Russia \\ Received 15 March 2019, Accepted 20 November 2020
}

Original Text (C) Shchanitsyn I.N., Shvarts E.Yu., Ishmukhametova R.A., Vozdeeva A.S., 2019, published in Saratov Journal of Medical Scientific Research 2019; 15 (1): 190-199.

(C) 2020, Shchanitsyn I.N., Shvarts E.Yu., Ishmukhametova R.A., Vozdeeva A.S.

(C) 2020, Saratov Medical Journal

\begin{abstract}
:
Objective: to identify the most important predictors of carotid artery stenosis in ambulatory patients of Saratov and Saratov Oblast, using multivariate analysis, and to specify an ideal patient for ultrasonographic screening.

Materials and methods. In 2014-2018, field consultations and ultrasonographic examinations were performed for asymptomatic patients with suspected carotid artery disease at outpatient clinics of Saratov and Saratov Oblast. Such patients were referred for screening by neurologists and general practitioners. The study encompassed 470 medical charts. The multivariate regression analysis was performed to identify independent predictors of carotid artery stenosis of 50 per cent or more.

Results. Carotid artery stenosis of $\geq 30 \%$ was detected in $24.5 \%$ (i.e., 115 of 470 ) of study participants; of $\geq 50 \%$ in $10.2 \%$ ( 48 of 470 ) patients, and of $\geq 70 \%$ stenosis in $2.9 \%$ (14/470) of participants. The multivariate analysis revealed that the odds of finding stenosis of $\geq 50 \%$ in patients, selected by neurologists and general practitioners for ultrasonographic screening, were significantly higher in the presence of the following factors: age exceeding 72, male gender, acute cerebrovascular event in anamnesis > 6 months ago, atherosclerosis of leg arteries, and episodes of speech impairment. We developed the point scale for risk assessment. A point scale for risk assessment has been created. In the absence of prognostic factors, the absolute risk of detecting stenosis $\geq 50 \%$ was just $3 \%$, with 1 point it was $16 \%$, and with 4 points it amounted to $>50 \%$.

Conclusion. Our analysis enabled us to specify the most significant predictors of carotid artery stenosis in patients observed at outpatient clinics of Saratov and Saratov Oblast, and to obtain a patient model helping to optimize optimize selection for ultrasonographic examination.
\end{abstract}

Keywords: carotid artery stenosis, asymptomatic carotid stenosis, ultrasonography, screening.

Cite as Shchanitsyn IN, Shvarts EYu, Ishmukhametova RA, Vozdeeva AS. Ultrasonography screening of carotid arteries in asymptomatic patients. Saratov Medical Journal 2020; 1(2): 00204

Correspondence to Ivan N. Shchanitsyn. Тел.: +7 (964) 879 9466; E-mail: dr.green@list.ru

\section{Introduction}

Stroke is among foremost causes of death and disability in the Russian Federation. In Saratov Oblast, the incidence of stroke in 2016 was 90.2 cases per 100 thousand inhabitants [1]. Atherosclerosis of the aortic arch vessels is the main cause of ischemic strokes, accounting for one-fifth of all strokes, while up to $80 \%$ of these events occur without previous symptoms. This fact justifies the need to examine patients who belong to risk groups. The rate of carotid stenosis progression cannot be accurately predicted. The likelihood of its rapid development is approximately the same as the probability of its stable course.

Carotid stenosis is most often diagnosed after a stroke or if the patient has symptoms of transient ischemic attacks (TIA), such as temporary speech impairment; dizziness and confusion; sudden loss or deterioration of vision; facial numbness on one side; weakness in one arm, or leg, or one side of the body. Patients with atherosclerotic lesions of carotid arteries are considered symptomatic if they have had TIA or ischemic stroke in the region of carotid artery stenosis within the last six months [2]. However, in most cases, patients are unaware of the presence of significant stenosis, since this pathology may not manifest itself in any way. The prevalence of significant asymptomatic stenosis of carotid arteries in the general population, according to different studies, ranges from o to $3.1 \%[3,4]$. Even if stenosis of carotid arteries is asymptomatic, the patient is at increased risk, hence the prognosis of stroke development within a year increases by $3 \%$ annually, despite up-to-date medical treatment [5].

Every year, stenosis of carotid arteries, as well as atherosclerosis in general, are diagnosed at a younger age than before. Early detection of lesions in the carotid arteries would allow to correct risk factors and prescribe modern medicamentous therapy to prevent the progression of stenosis, and in case of significant damage, to propose timely surgical treatment in order to prevent stroke.

Carotid artery duplex scan is used as a screening method to assess the risk of atherosclerotic lesions of the carotid arteries [2]. Although cervical auscultation is a standard part of physical examination, murmur detection is more closely correlated with systemic atherosclerosis than with significant carotid stenosis. The sensitivity and positive predictive value for hemodynamically significant stenosis is low. The NASCET (North American Symptomatic Carotid Endarterectomy Trial) study established that sensitivity of carotid arteries 
auscultation is only $63 \%$, and the specificity is $61 \%$ [6]. Several studies have stated that the sensitivity of auscultation of the carotid arteries for detecting stenosis of over $70 \%$ varies from 46 to $77 \%$, and the specificity ranges from 61 to $98 \%[6,7]$. In a broad study, the prevalence of asymptomatic carotid stenosis of over $35 \%$ in patients without murmur symptoms was $6.6 \%$, and the prevalence of stenosis of over $75 \%$ was $1.2 \%$ [8].

Ultrasonography of the carotid arteries is widely available and associated with a low risk and discomfort. However, medical and economic studies have not shown the feasibility of mass ultrasound screening of the adult population [2, 911]. Besides, low specificity of carotid artery duplex scan in routine mass screening may lead to abundant false positive results [12], thereby increasing the frequency of unnecessary aggressive medicamentous and surgical treatment.

In the present-day realities of the Russian Federation, ultrasonographic screening is limited due to large financial costs, as well as due to low provisioning of regional polyclinics, especially in smaller towns and urban-type settlements, with equipment and ultrasound examination specialists. Thus, despite the fact that ultrasonography is a simple and effective method for diagnosing lesions of the carotid arteries, screening of the entire population with an asymptomatic course of the disease is impractical. It is necessary to identify risk groups of carotid artery disease and purposefully conduct examination of these patients in order to increase the effectiveness of ultrasound screening. Several population studies have shown that conventional risk factors, including smoking, high low-density lipoprotein cholesterol content, low high-density lipoprotein cholesterol content, hypertension and diabetes mellitus, increase the risk of carotid atherosclerosis in men and women regardless of their age [4]. We analyzed already published studies to detect risk factors for carotid artery disease, as well as carried out a study, based on polyclinics in Saratov Oblast, during which we attempted to identify the most significant predictors, using multivariate analysis, and clarify the optimal patient model for ultrasonography screening in our region.

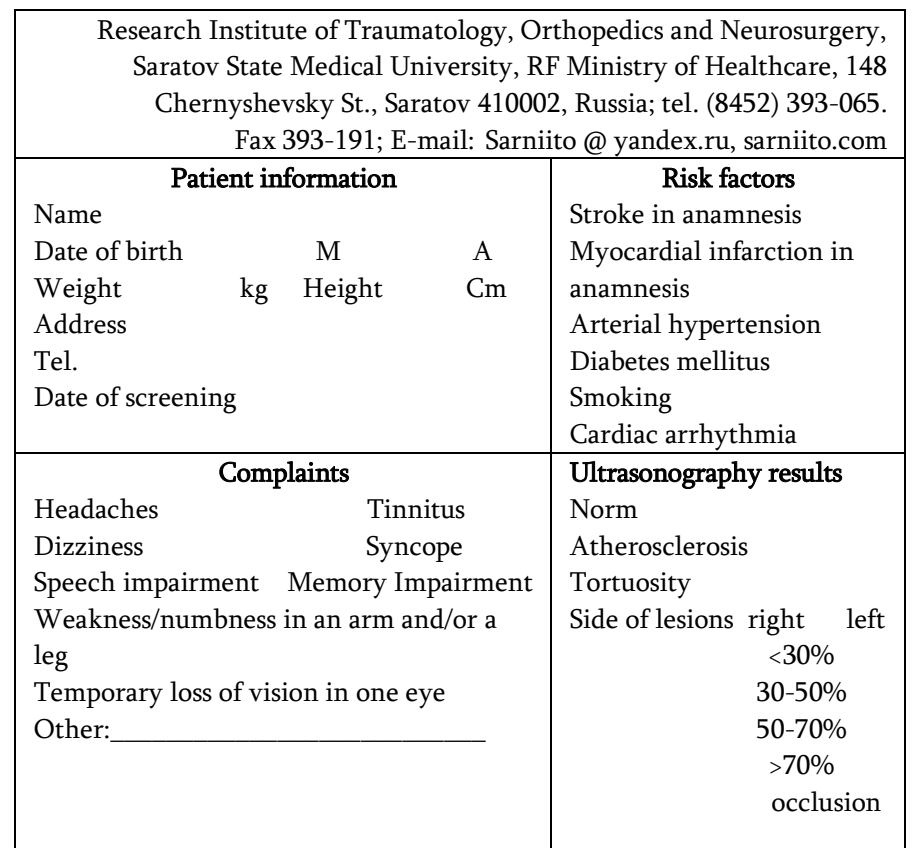

Figure 1. Protocol for ultrasonographic screening of carotid arteries

(C) 2020, Saratov State Medical University, Saratov, Russia

(C) 2020, LLC Innovative Medical Technologies, Saratov, Russia

(C) 2020, LLC Science and Innovations, Saratov, Russia

\section{Materials and methods}

In the clinics of Saratov and Saratov Oblast (the cities of Balashov, Rtishchevo, Krasnoarmeysk, Pugachev, Balakovo, Engels), over 2014 - 2018, field consultations and examination of patients with suspected carotid arteries lesions, referred by neurologists and therapists, were conducted. The survey encompassed the collection of complaints and anamneses; for each patient, a questionnaire was filled out, where, in addition to passport and anthropometric data, risk factors and ultrasonography results were noted (Figure 1).

Over 600 patients were examined, and 470 correctly completed patient medical records were finally included into the study. The study did not include symptomatic patients i.e., those with a stroke or TIA over the last 6 months; transient or persistent focal neurological symptoms; previously identified carotid artery stenosis; as well as with incomplete or incorrectly completed questionnaires. The study was carried out in accordance with Good Clinical Practice and the principles of the Declaration of Helsinki. Informed consent was obtained from all participants prior to their enrollment. Ultrasonography was conducted on the Medison SonoAce $\mathrm{R}_{3}$ portable device. A broadband linear sensor with a scanning frequency of $5-15 \mathrm{MHz}$ and a broadband convex sensor with a frequency of 2.0-5.0 $\mathrm{MHz}$ were used. In the process of examination, we used B-mode imaging, color and power Doppler mapping, and Doppler ultrasonography. The presence of stenosing plaques in the bifurcation of the carotid artery was considered with subsequent gradation of stenosis degree sensu the ECST criteria [13]: <30, 30-50\%, 50-70\%, and >70 (\%).

Based on examination results, patients with a degree of stenosis of $>50 \%$ were allocated to a separate group, since they needed continuing attendance and appointment of optimal medicamentous therapy or surgical intervention. Statistical data processing was carried out, using Microsoft Office Excel 13 with the application package and IBM SPSS Statistics 21.0. The distribution normality was checked using the Kolmogorov-Smirnov and Shapiro-Wilk tests. When distribution of parameter values was not normal, the group median and interquartile range were used to describe quantitative features. Qualitative traits were presented in absolute values and percentages.

When comparing groups by quantitative characteristics, the methods of nonparametric statistics were used, such as Mann-Whitney U test (two-sided test). Comparison of groups by qualitative characteristics was carried out by evaluating contingency tables and calculating the Pearson's $\chi^{2}$ criterion (two-sided test; Fisher's exact test at the number of observations in the table cells less than 5). The revealed differences $(\mathrm{p}<0.2)$ were further included in the multivariate analysis. To determine the optimal cut-off values of continuous variables, sensitivity and specificity analysis was used to construct ROC curves and calculate the Youden's index (Youden's $J$ statistic: $J=$ sensitivity + specificity -1 ).

Multivariate analysis was performed, using binary logistic regression via forced inclusion with an inclusion probability of 0.05 and an exclusion probability of 0.10 or above. The odds ratios (OR) were determined with a 95\% confidence interval (significance level $\mathrm{p}<0.05$ ). The predictors identified in the multivariate analysis were used to create a scoring scale for the risk of detecting carotid artery stenosis $\geq 50 \%$. Discriminant analysis was used to estimate the normalized coefficients of the canonical discriminant function of 
independent predictors. We then used the hierarchy of these coefficients to create the predictive scale by converting them into integer components (points). The absolute risk of detecting stenosis (\%) was computed for different scores.

\section{Results}

A total of 470 completed questionnaire cards were included into the study. Among patients, referred by neurologists and therapists, the vast majority were women $(81.7 \%, 382 / 470)$. The age of patients ranged from 17 to 87 years; the median age was $67(60 ; 75)$ years. Most were overweight: body mass index (BMI) was $28(25 ; 32) \mathrm{kg} / \mathrm{m} 2$. Among the risk factors were the following: arterial hypertension (62\%), cardiac arrhythmias (37\%), a history of acute cerebrovascular accident (over 6 months) (17\%), diabetes mellitus (17\%), ischemic heart disease (16\%), a history of myocardial infarction (16\%), atherosclerosis of leg arteries (11\%), smoking (8\%). The main complaints were: dizziness (66\%), headaches (61\%), tinnitus (56\%), memory loss (63\%), visual impairment (15\%), episodes of speech impairment (7\%), and episodes of syncope (7\%).

Among these patients, carotid artery stenosis $\geq 30 \%$ was detected in $24.5 \%(115 / 470)$. Stenosis $\geq 50 \%$ was found in $10.2 \%(48 / 470)$ of patients. Consequently, on average, one patient of ten had a lesion of carotid arteries, requiring dynamic monitoring and aggressive treatment of atherosclerosis. Stenosis $\geq 70 \%$ was detected in $2.9 \%$ study participants (14/470). These were the patients, for whom surgical treatment may has already been indicated (approximately every thirtieth patient). Of these, 12 patients underwent further carotid endarterectomy or stenting at the Department of Nerosurgery of the Research Institute of Traumatology, Orthopedics and Neurosurgery, SSMU.

Table 1 shows main characteristics of all patients and a comparison of two groups, depending on the presence of carotid artery stenosis $\geq 50 \%$. The revealed significant differences between the groups $(p<0.2)$ were further included in multivariate analysis (binary logistic regression). To convert quantitative characteristics (age and height) into qualitative traits, threshold values were determined, using sensitivity and specificity analysis, while constructing ROC curves, and the Youden's index was calculated.

Multivariate analysis showed that the risk of detecting stenosis $\geq 50 \%$ in the group of patients, selected by neurologists and therapists for screening, was significantly higher in the presence of the following factors: age over 72 years old, male gender, acute cerebrovascular accident in the history of over six months, atherosclerosis of leg arteries, and episodes of speech impairment (Figure 2).

In the course of discriminant analysis, a scoring scale for detecting carotid artery stenosis of $\geq 50 \%$ among patients, selected for screening, was obtained (Table 2).

In the absence of these prognostic factors, the absolute risk of detecting stenosis $\geq 50 \%$ was only $3 \% ; 16 \%$ with a score of 1 point; and over $50 \%$ with a score of 4 points (Table 3).

\section{Discussion}

At the moment, there is no direct evidence of the need for screening to detect asymptomatic carotid stenosis. There are several opinions on the need for mass screening. Due to potentially adverse effects of false positive and false negative results in the general population, lack of cost effectiveness, and low absolute benefit of various types of invasive interventions, the American Heart Association guidelines for the primary prevention of ischemic stroke do not support the idea of mass population screening for asymptomatic carotid stenosis. From the point of view of the US Preventive Services Task Force, as well as American Heart Association/American Stroke Association, American College of Cardiology, and others, it is not recommended to screen for carotid stenosis in patients without neurologic symptoms and a history of stroke or TIA - i.e., existing screening methods have insufficient sensitivity, which could lead to unnecessary surgery and serious complications (death, stroke, or myocardial infarction) [14-16]. Russian national recommendations are as follows, 'Ultrasonographic carotid artery duplex scan is not recommended for routine screening of neurologically asymptomatic patients who do not have clinical manifestations or risk factors for atherosclerosis' (Evidence C) $[2]$.

Table 1. Descriptive statistics of all patients and comparison of two groups based on the presence of carotid artery stenosis of $\geq \mathbf{5 0} \%$

\begin{tabular}{|c|c|c|c|c|}
\hline Parameters* & $\begin{array}{l}\text { All patients } \\
\qquad(\mathrm{n}=470)\end{array}$ & $\begin{array}{c}\text { Stenosis of } \\
<50 \% \text { or none } \\
(\mathrm{n}=422)\end{array}$ & $\begin{array}{l}\text { Stenosis of } \geq 50 \% \\
(n=48)\end{array}$ & $p^{* *}$ \\
\hline Age, years & $67(60-75)$ & $66.5(60-74)$ & $72(64-80)$ & 0.001 \\
\hline $\begin{array}{l}\text { Male gender, } \\
\text { n (\%) }\end{array}$ & $88(18.7)$ & $66(15.6)$ & $22(45.8)$ & $\begin{array}{c}<0.00 \\
1\end{array}$ \\
\hline Weight, kg & $73(65-85)$ & $73(65-85)$ & $76(70-83)$ & 0.271 \\
\hline Height, cm & $\begin{array}{c}162(156- \\
167)\end{array}$ & $162(156-166)$ & $165(159-170)$ & 0.003 \\
\hline BMI, $\mathrm{kg} / \mathrm{m}^{2}$ & $28(25-32)$ & $28(25-31)$ & $28(26-30)$ & 0.529 \\
\hline \multicolumn{5}{|l|}{ Risk factors: } \\
\hline $\begin{array}{l}\text { ACA in } \\
\text { anamnesis over } \\
6 \text { months, } n(\%)\end{array}$ & 79 (16.8) & $62(14.7)$ & $17(35.4)$ & 0.001 \\
\hline $\begin{array}{lr}\text { MI } & \text { in } \\
\text { anamnesis, } & \mathrm{n} \\
(\%) & \\
\end{array}$ & $42(8.9)$ & $35(8.3)$ & 7 (14.6) & 0.176 \\
\hline ASHD, n (\%) & $73(15.5)$ & $61(14.5)$ & $12(25.0)$ & 0.089 \\
\hline $\mathrm{DM}, \mathrm{n}(\%)$ & $79(16.8)$ & $70(16.6)$ & $9(18.8)$ & 0.686 \\
\hline $\mathrm{AH}, \mathrm{n}(\%)$ & $293(62.3)$ & $263(62.3)$ & $30(62.5)$ & 0.557 \\
\hline $\mathrm{CA}, \mathrm{n}(\%)$ & $172(36.6)$ & 154 936.5) & $18(37.5)$ & 0.876 \\
\hline $\begin{array}{l}\text { Atherosclerosis } \\
\text { of leg arteries, } \\
\text { n (\%) }\end{array}$ & $50(10.6)$ & $40(9.5)$ & $10(20.8)$ & 0.024 \\
\hline Smoking, n (\%) & $36(7.7)$ & $30(7.1)$ & $6(12.5)$ & 0.244 \\
\hline \multicolumn{5}{|l|}{ Complaints: } \\
\hline $\begin{array}{l}\text { Headaches, } \\
\text { n (\%) }\end{array}$ & $287(61.1)$ & $255(60.4)$ & $32(66.7)$ & 0.438 \\
\hline $\begin{array}{l}\text { Dizziness, } \\
\text { n (\%) }\end{array}$ & $312(66.4)$ & $283(67.1)$ & $29(60.4)$ & 0.420 \\
\hline $\begin{array}{l}\text { Speech } \\
\text { impairment, } \\
\text { n (\%) }\end{array}$ & $32(6.8)$ & $23(5.5)$ & $9(18.8)^{* *}$ & 0.003 \\
\hline $\begin{array}{l}\text { Weakness and } \\
\text { numbness of } \\
\text { legs, } n(\%)\end{array}$ & $265(56.4)$ & $236(55.9)$ & $29(60.4)$ & 0.646 \\
\hline $\begin{array}{l}\text { Temporary loss } \\
\text { of vision, } \mathrm{n}(\%)\end{array}$ & $68(14.5)$ & $60(14.2)$ & $8(16.7)$ & 0.665 \\
\hline Tinnitus, n (\%) & $261(55.5)$ & $233(55.2)$ & $28(58.3)$ & 0.760 \\
\hline Syncope, n (\%) & $35(7.4)$ & $30(7.1)$ & $5(10.4)$ & 0.385 \\
\hline $\begin{array}{l}\text { Memory } \\
\text { impairment, } \\
\mathrm{n}(\%)\end{array}$ & $296(63)$ & $264(62.6)$ & $32(66.7)$ & 0.638 \\
\hline
\end{tabular}




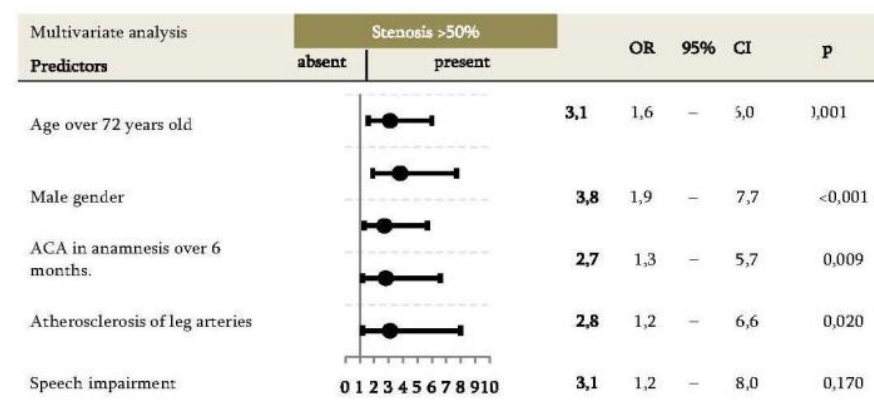

$A C A$ - scute cerebrovascular accident, $O R$ - odds ratio, CI - confidence interval.

Figure 2. Predictors of detecting carotid artery stenosis over $50 \%$ among patients selected for screening (multivariate analysis)

Table 2. Risk score for detecting carotid artery stenosis $\mathbf{2 5 0} \%$ among patients selected by physicians and neurologists for screening

\begin{tabular}{|l|c|c|}
\hline Predictive factor & $\begin{array}{c}\text { Discriminant } \\
\text { function coefficient }\end{array}$ & $\begin{array}{c}\text { Predictive model } \\
\text { score }\end{array}$ \\
\hline Age over 72 years old & 0.396 & 1 \\
\hline Male gender & 0.591 & 2 \\
\hline $\begin{array}{l}\text { ACA in anamnesis over 6 } \\
\text { months }\end{array}$ & 0.364 & 1 \\
\hline $\begin{array}{l}\text { Atherosclerosis of leg } \\
\text { arteries }\end{array}$ & 0.332 & 1 \\
\hline Speech impairment & 0.354 & 1 \\
\hline
\end{tabular}

Description of the model: Wilks' lambda is $0.887, \chi^{2}$ is 55.12 , p $<0.001 ;{ }^{*}$ - rounded up to an integer, multiple of the minimum coefficient of the discriminant function; ACA - acute cerebrovascular accident.

Table 3. Prevalence of carotid artery stenosis $\geq 50 \%$ vs. presence of risk factors

\begin{tabular}{|c|c|c|}
\hline $\begin{array}{c}\text { Score } \\
\text { (number of } \\
\text { points) }\end{array}$ & $\begin{array}{c}\text { Number of patients with } \\
\text { stenosis (total number of } \\
\text { patients) }\end{array}$ & $\begin{array}{c}\text { Absolute risk of } \\
\text { detecting stenosis } \\
\geq 50 \%\end{array}$ \\
\hline 0 & $6(208)$ & $3 \%$ \\
\hline 1 & $11(132)$ & $16 \%$ \\
\hline 2 & $12(69)$ & $24 \%$ \\
\hline 3 & $10(44)$ & $31 \%$ \\
\hline 4 & $6(12)$ & $53 \%$ \\
\hline 5 & $3(5)$ & $60 \%$ \\
\hline
\end{tabular}

Despite available recommendations and research, the issue of the need to diagnose stenosis in asymptomatic people remains open. Is it worth identifying and subsequently subjecting asymptomatic patients to further examinations and treatment? The term asymptomatic carotid artery stenosis was proposed in the ACAS study (Asymptomatic Carotid Artery Stenosis Study) in 1995 [17]. It means the absence of transient or persistent focal neurological symptoms, while the patient may have certain nonspecific signs of dyscirculatory encephalopathy.

Some researchers, primarily cardiovascular surgeons, insist on the need to actively identify and treat patients with asymptomatic carotid stenosis. They argue that the first clinical manifestation of carotid artery stenosis is often represented by the stroke. Based on the results of randomized clinical trials (RCTs), conducted in the 1990s, carotid artery occlusion is detected, when restoration of full cerebral blood flow is no longer possible, in a large percentage of ischemic stroke cases. However, in three studies, evaluating carotid endarterectomy (CEA) benefits in asymptomatic patients ACAS [17], VACS (Veterans Affairs Cooperative Study) [18], ACST (Asymptomatic Carotid Surgery Trial) [19] - the absolute risk reduction of ipsilateral stroke with stenosis $>60 \%$ after the surgery was significant, even though quite small: 5.9\% (ACAS); and 5.4\% (ACST), with women having either no risk reduction, or smaller reduction than in men (Table 4).

Opponents of active detection and surgical treatment of asymptomatic stenosis, who are mainly neurologists, also point out significant limitations of the RCTs. For example, the studies did not include patients selected for outpatient screening. In addition, many of registered patients were not completely asymptomatic, 20 to $24 \%$ had a history of carotid endarterectomy, and $25-32 \%$ had a history of TIA or stroke over 6 months prior to the surgery. The ACAS study included patients with symptoms related to the contralateral artery (over 45 days before surgery). Medicamentous therapy has not been well standardized. Although all patients received aspirin, only $7-11 \%$ received statins in 1993 , although $80-82 \%$ did in 2007 studies. Currently, best medical therapy is a combination of antiplatelet therapy (usually dual therapy), intensive medicamentous treatment of arterial hypertension, dyslipidemia, diabetes mellitus, as well as lifestyle changes aimed at quitting smoking, preventing obesity and increasing the frequency of physical activity. Surgeons have been carefully selected to participate in clinical trials based on observed low morbidity and mortality rates.

Table 4. Randomized clinical trials comparing surgical vs. medicamentous treatment for asymptomatic carotid artery stenosis

\begin{tabular}{|c|c|c|c|c|c|c|c|}
\hline $\begin{array}{l}\text { Clinica } \\
1 \text { study }\end{array}$ & $\begin{array}{c}\text { Stenosis } \\
\text { degree }\end{array}$ & $\begin{array}{l}\text { Sample } \\
\text { size }\end{array}$ & $\begin{array}{c}\text { Observat } \\
\text { ion time, } \\
\text { years }\end{array}$ & $\begin{array}{l}\text { Primary } \\
\text { effects }\end{array}$ & $\begin{array}{c}\text { CEA, } \\
\%\end{array}$ & $\begin{array}{c}\text { OMT, } \\
\%\end{array}$ & $p$ \\
\hline $\begin{array}{l}\text { VACS } \\
(1983- \\
1987)\end{array}$ & $250 \%$ & 444 & 4 & $\begin{array}{c}\text { TIA, transient } \\
\text { blindness, or } \\
\text { stroke }\end{array}$ & 8.0 & 20.6 & 0.001 \\
\hline $\begin{array}{l}\text { ACAS } \\
(1987- \\
1993)\end{array}$ & $\geq 60 \%$ & 1662 & 2.7 & $\begin{array}{l}\text { Stroke or } \\
\text { death }\end{array}$ & 5.1 & 11.0 & 0.004 \\
\hline \multirow{2}{*}{$\begin{array}{l}\text { ACST- } \\
1 \\
(1993- \\
2003)\end{array}$} & \multirow{2}{*}{$\geq 60 \%$} & \multirow{2}{*}{3120} & 5 & \multirow{2}{*}{$\begin{array}{c}\text { Stroke or } \\
\text { death }\end{array}$} & 6.9 & 10.9 & $\begin{array}{c}0.000 \\
1\end{array}$ \\
\hline & & & 10 & & 13.4 & 17.9 & 0.009 \\
\hline
\end{tabular}

TIA - transient ischemic attack; CEA - carotid endarterectomy; OMT - optimal medical therapy; VACS - Veterans Affairs Cooperative Study [18]; ACAS - Asymptomatic Carotid Artery Stenosis Study [17]; ACST-1 -Asymptomatic Carotid Atherosclerosis Study [19]. 
Table 5. Randomized clinical trials currently underway to compare different treatment techniques for asymptomatic carotid stenosis

\begin{tabular}{|c|c|c|c|c|c|c|c|}
\hline & $\begin{array}{c}\text { Compariso } \\
\mathrm{n}\end{array}$ & Started & $\begin{array}{l}\text { Inclusion } \\
\text { criteria }\end{array}$ & $\begin{array}{l}\text { Recruite } \\
\text { d } \\
\text { (total/goa } \\
\text { l) }\end{array}$ & Outcomes & Duration & Results \\
\hline $\begin{array}{l}S \\
P\end{array}$ & $\begin{array}{l}\text { CEA+OMT } \\
\text { vs. OMT }\end{array}$ & & & & & & \\
\hline $\begin{array}{l}\text { A } \\
\text { C } \\
\text { E } \\
- \\
2\end{array}$ & $\begin{array}{l}\text { CAS+OMT } \\
\text { vs. OMT }\end{array}$ & 2008 & $\begin{array}{c}\text { Stenosis } \geq 70 \% \\
\text { (based on USG) }\end{array}$ & $\begin{array}{c}513 / 1998 \\
(2013)\end{array}$ & $\begin{array}{l}\text { 30-day stroke/death, } \\
\text { ipsilateral stroke } 5 \text { years }\end{array}$ & 5 years & $\begin{array}{c}\text { 30-day stroke / death: } 1.97 \%- \\
0 \% \text { (CEA - OMT), } 2.54 \%-0 \% \\
(\text { CAS - OMT })^{*}\end{array}$ \\
\hline $\begin{array}{l}\mathrm{E} \\
\mathrm{C} \\
\mathrm{S} \\
\mathrm{T} \\
- \\
2\end{array}$ & $\begin{array}{l}\text { CEA/CAS } \\
\text { vs. OMT }\end{array}$ & 2012 & $\begin{array}{l}\text { Stenosis } \geq 50 \% \\
\text { (based on USG) }\end{array}$ & $\begin{array}{l}364 / 2000 \\
\text { (October } \\
2018)\end{array}$ & $\begin{array}{c}\text { Stroke, ICH, death } 2 \\
\text { years; stroke and non- } \\
\text { stroke death 5-10 years }\end{array}$ & 10 years & After 2022 \\
\hline $\begin{array}{l}\mathrm{C} \\
\mathrm{R} \\
\mathrm{E} \\
\mathrm{S} \\
\mathrm{T} \\
- \\
2\end{array}$ & $\begin{array}{l}\text { CEA vs. } \\
\text { OMT }\end{array}$ & 2014 & $\begin{array}{c}\text { Stenosis } \geq 70 \% \\
\text { based on AG or } \\
\text { USG (obvious) }\end{array}$ & $\begin{array}{l}1100 / 248 \\
0 \\
(\text { Februar } \\
\text { y 2019) }\end{array}$ & $\begin{array}{l}\text { Periprocedural } \\
\text { stroke/death, ipsilateral } \\
\text { stroke } 4 \text { years }\end{array}$ & 6 years & After 2020 \\
\hline
\end{tabular}

SPACE - Stent Protected Angioplasty versus Carotid Endarterectomy; ECST - European Carotid Surgery Trial; CREST - Carotid Revascularization and Medical Management for Asymptomatic Carotid Stenosis Trial; AG -angiography; USG - ultrasonographic examination; CEA - carotid endarterectomy; CAS - carotid artery stenting; OMT - optimal medical therapy; ICH - intracerebral hemorrhage; * - slow recruitment of patients, did not recruit the required number, continued monitoring of already recruited patients.

Thus, the presence of asymptomatic stenosis is not yet $100 \%$ indication for surgery. More research is needed to compare current optimal medicamentous therapy and surgical management for asymptomatic stenosis. A number of such studies are currently underway with results expected after 2020-2022. (Table 5).

The planned study CREST-2 (Carotid Revascularization and Medical Management for Asymptomatic Carotid Stenosis Trial) may be one of the most informative for future recommendations. CREST-2 plans to enroll 2,400 patients with stenosis greater than $70 \%$ that will be randomly assigned to groups. Different management tactics will be compared. The carotid artery stenting group with optimal medicamentous therapy will be compared with the optimal medicamentous therapy group. The carotid endarterectomy group with optimal medicamentous therapy will be compared with the optimal medicamentous therapy group [20]. The randomized clinical trial SPACE-2 (Stent Protected Angioplasty versus Carotid Endarterectomy), which was conducted in Germany, Austria and Switzerland, had methods similar to CREST-2, but, unfortunately, due to problems with patient selection, instead of planned 1998 patients, only 513 patients were recruited. The study per se was completed, but the follow-up study of already recruited patients continues for inclusion in further meta-analyzes [21].

Given the fact that there is not only a significant improvement in pharmaceutical drug treatment, but also a decrease in complications after surgical treatment, the future outcome of the research is not clear [22]. Currently, in surgical treatment, the risk of stroke / death is $1.2 \%$, the risk of death is $0.4 \%$, which is associated with a higher technical level of the operation, increased use of statins and dual antiplatelet therapy; more effective postoperative blood pressure control; more careful patient selection; centralized surgery of carotid arteries; patch use for suturing arteriotomy or performance of eversion carotid endarterectomy; and abandonment of open surgery in favor of stenting in high-risk patients. However, simple mathematical calculations show that, in the ACAS and ACST studies, 1000 patients with asymptomatic stenosis had to be operated to prevent 50-60 strokes, and 940-950 patients underwent unnecessary surgery. Even a significant improvement in surgical outcomes at this time would not significantly change these statistics. In simple terms, the reduction in the incidence of perioperative death / stroke is nothing less than good news for the individual patient, but in fact, it has little effect on reducing the number of patients who would ultimately undergo unnecessary intervention [23].

Life expectancy is also a very important criterion for assessing the effectiveness of the discussed treatments. Comparing the ratios of postoperative deaths / strokes after surgery and deaths from natural causes / stroke without surgery, we can conclude that they are approximately equal. Thus, the question arises: is it advisable to operate on asymptomatic screened-only patients over 75 years of age? Indeed, these patients usually have several competing diseases that are potentially life-threatening.

Recent recommendations from various medical communities agree that surgery is indicated for a specific group of asymptomatic patients with risk factors. In addition to the need to identify patients who already need surgical treatment, screening makes it possible to promptly start aggressive medicamentous therapy, identify a group of patients for follow-up (Russian national guidelines indicate 
the need to repeat ultrasonography every year to assess the progression of the disease in patients with stenosis over $50 \%$ ), and prevent the development of a stroke. It has been shown that, even in the presence of obvious indications for statin therapy (for example, after suffering a cerebrovascular accident or myocardial infarction), many doctors persistently refuse to prescribe these pharmaceutical drugs, referring to the danger of side effects [24], or prescribing them in insufficient doses [25]. Despite the fact that frequency and effectiveness of antihypertensive treatment has increased, the achievement of target blood pressure values in Russia is significantly lower than in most developed countries [26]. Hence, the need to identify risk groups and standardize medicamentous therapy for atherosclerotic lesions of carotid arteries in Russia is an important factor in favor of screening.

From the economic point of view, conducting total screening using ultrasonography is unprofitable and requires unreasonable labor costs [27]. Screening can only be costeffective when it is conducted in a population with a higher prevalence of the disease [28]. According to Yin D, et al. (1998), screening is cost-effective if the prevalence of carotid stenosis is $4.5 \%$ or above, the specificity of the screening test (carotid artery duplex scan) is $91 \%$ or more, the stroke rate in patients with optimal medicamentous therapy is $3.3 \%$ or more, the relative risk reduction for stroke is not less than $37 \%$, and the cost of ultrasound examination is US $\$ 300$ or less [29].

One of the limitations of ultrasound screening is the large number of false positive and false negative results. Sensitivity and specificity for detecting carotid artery stenosis greater than $70 \%$ is $90 \%$ (95\% CI 84-94\%) and 94\% (95\% CI 88$97 \%)$, respectively [4]. For example, for a population where the adult population is 100,000 and the prevalence of significant carotid artery stenosis is $1 \%$, ultrasonography will yield 940 true positive results and 7920 false positives (with a specificity of 92\%). If additional examinations are not carried out, then many unnecessary surgical interventions may follow [4].

Thus, total screening for carotid artery pathology has neither economic nor clinical justification. However, there is evidence of the feasibility of screening and subsequent preventive surgical treatment within risk groups [30]. The American neuroimaging community has recommended screening among people over 65 years of age who have three or more risk factors for cardiovascular disease as opposed to full screening of all population. The community recommends screening among asymptomatic patients with carotid murmur who are potential candidates for carotid revascularization, and screening for those undergoing coronary artery bypass graft.

Following foreign and Russian national recommendations, we could single out the factors of high stroke risk: silent cerebral infarct sensu computed tomography (CT) or magnetic resonance imaging (MRI); progression of stenosis degree; unstable plaque sensu ultrasonography, CT or MRI (large area of the plaque, large area of the soft core of the plaque, hypoechoic plaque, hemorrhages in the plaque according to MRI, spontaneous embolization sensu transcranial Doppler); decreased cerebrovascular reserve; history of TIA or acute cerebrovascular accident in the contralateral arterial network, diabetes mellitus, male gender, age over 60 years old. The patients with above-listed factors, even if they are with asymptomatic course of the disease, are most likely indicated for surgical treatment and, accordingly, for ultrasound screening.

Russian national guidelines recommend to pay attention to the following markers and risk factors when conducting ultrasonography: previous acute cerebrovascular accident or TIA, damage to other vascular networks (arteriosclerotic heart disease, atherosclerosis of leg arteries, aortic aneurysm, etc.), hereditary hyperlipidemia, diabetes mellitus, bad habits (smoking, alcohol abuse), arterial hypertension, thrombophilia, and overweight [2]. Carotid artery duplex scan is recommended to neurologically asymptomatic patients with auscultatory murmur over the carotid arteries, over 50 years old, who have two or more of the following risk factors: arterial hypertension, hyperlipidemia, smoking, family history among close relatives with cases of atherosclerosis when under 60 years of age, or family history of ischemic stroke (level of evidence $\mathrm{C}$ ).

However, despite the significance of the listed risk factors for stroke, it is problematic to use these data in actual practice, since almost every patient over 60 years old, who seeks a help of neurologist or therapist, has one or more of the listed risk factors. In Russia, due to high morbidity and mortality from stroke, the low availability of ultrasonography in many regions, the issue of screening is more acute.

In studies on various populations, the following risk factors for revealing significant stenosis of the carotid arteries were identified: age over 65 years old, smoking, hypercholesterolemia, cardiovascular diseases, and arterial hypertension [31, 32]. As a result of our study, we identified the most significant risk factors and developed a point scale, the use of which could help in deciding whether it is necessary to conduct an ultrasonography: age over 72 years old, male gender, a history of acute cerebrovascular accident over 6 months, atherosclerosis of leg arteries, and episodes of speech impairment. The presence of at least one factor increases the likelihood of detecting carotid artery stenosis by $13 \%$, while the presence of four factors augments the probability by $50 \%$.

It is worth noting that the most frequent complaints, with which neurologists and therapists sent patients for ultrasound screening (headaches, dizziness, tinnitus, weakness and numbness in the extremities), had no connection with the detection of the carotid arteries stenosis. This fact suggests that, first of all, it is necessary to pay attention to risk factors rather than to non-specific patient complaints.

During the analysis, we noticed that there were just 16$17 \%$ of the patients, selected for ultrasonography, with such risk factors, as diabetes mellitus and coronary heart disease. Perhaps, this is due to the fact that such patients are more often observed by endocrinologists and cardiologists. Probably, with an increase in the proportion of such patients, these risk factors would become significant in our study. From this finding, we can conclude that such specialist physicians should be involved in the selection of patients for the screening.

An episode of acute cerebrovascular accident in the anamnesis over 6 months ago has become a significant risk factor. This evidence once again confirms the fact that, first of all, it is necessary to conduct ultrasonography in patients after acute cerebrovascular accident and TIA (episodes of speech impairment, episodes of temporary loss of vision in one eye, and episodes of weakness in half of the body), regardless of the limitation period. 
Male gender was the most significant predictor of carotid atherosclerosis. This is in line with the global statistics on the high prevalence of atherosclerosis in men. It should be noted that, among the patients selected for ultrasound screening, the absolute risk of detecting carotid artery stenosis in men with atherosclerosis of leg arteries increased by almost $30 \%$. Perhaps, it is necessary to provide greater involvement of general surgeons into selecting patients for screening, because they observe patients with atherosclerotic lesions of the arteries of lower extremities in most polyclinics.

Our research had a number of limitations:

- Only 470 patients were included in the analysis. When assessing the required sample size using the calculation formula sensu M. Bland method, the power of our study does not exceed $80 \%$, which corresponds to a study of average accuracy;

- The sample was biased, since the patients were selected for screening by therapists and neurologists, and we did not conduct weighting to obtain greater uniformity of the sample;

- Major, but not all, risk factors were included in the questionnaire - i.e., family history, hypercholesterolemia, thrombophilia and some other factors were not taken into account;

- Conducting a comprehensive ultrasonography has disadvantages in the form of false positive and false negative results. For example, evaluating the accuracy and reliability of ultrasound examination to detect carotid stenosis in three meta-analyses and three large studies, Jonas DE, et al. (2014) reported a sensitivity of $98 \%$ (95\% CI, 97-100\%) and specificity of $88 \%$ (95\% CI $76-100 \%)$ for detecting carotid artery stenosis $\geq 50 \%$ [4]. There is no doubt that ultrasound screening in our study had lower values of sensitivity and specificity.

\section{Conclusion}

Our analysis enabled us to clarify the most significant predictors of carotid artery stenosis in patients observed in outpatient clinics of Saratov and Saratov Oblast, and to develop a patient model that would help optimize selection for ultrasound screening. The resulting patient model for ultrasonographic examination can be recommended to neurologists, therapists, cardiologists and related specialists. This model may help to refer patients to ultrasonography those, who actually need it most, which could make all the difference at regional polyclinics and hospitals, where ultrasonography of blood vessels is in high demand due to shortage of equipment and specialists.

\section{Acknowledgments}

The study was conducted in accordance with the Initiative Plan of Scientific Research Framework of Research Institute of Traumatology, Orthopedics and Neurosurgery, Saratov State Medical University of the RF Ministry of Healthcare No. 154018-04 Improving Methods of Diagnosis, Treatment and Prevention of Injuries and Diseases of the Musculoskeletal and Nervous Systems. Registration number: AAAA-A18118060790019-0.

\section{Conflict of interest}

The authors declare no conflict of interest.

\section{References}

1. Leonov SA, Golubev NA, Zaychenko NM. Federal Budgetary Institution of the RF Ministry of Healthcare 'Central Research Institute for Healthcare Organization and Informatization': Statistic data on circulatory system diseases. Moscow. 2017; 295. (In Russian).

2. Pokrovsky AV, Abugov SA, Alekyan BG, et al. National guidelines for treating patients with brachiocephalic arteries disorders. Angiology and Vascular Surgery 2013; (2): 1-70. (In Russian).

3. Waard DD, Morris D, Borst GJ, et al. Asymptomatic carotid artery stenosis: Who should be screened, who should be treated and how should we treat them? J Cardiovasc Surg (Torino) 2017; 58 (1): 3-12.

https://doi.org/10.23736/So021-9509.16.09770-6

4. Jonas DE, Feltner C, Amick HR, et al. Screening for asymptomatic carotid artery stenosis: A systematic review and meta-analysis for the US Preventive Services Task Force. Ann Intern Med 2014; 161 (5): 336-46. https://doi.org/10.7326/M14-0530

5. Gaba K, Ringleb PA, Halliday A. Asymptomatic carotid stenosis: Intervention or best medical therapy? Curr Neurol Neurosci Rep 2018; 18 (11): 80. https://doi.org/10.1007/s11910-018-0888-5

6. O'Brien M, Chandra A. Carotid revascularization: risks and benefits. Vasc Health Risk Manag 2014; (10): 403-16. https://doi.org/10.2147/VHRM.S48923

7. Le Fevre ML. Screening for asymptomatic carotid artery stenosis: US Preventive Services Task Force recommendation statement. Ann Intern Med 2014; 161 (5): 356-62. https://doi.org/10.7326/M14-1333

8. Russell EJ, Hetts SW, Bello JA, et al. ACR-ASNR-SIR-SNIS practice parameter for the performance of diagnostic cervicocerebral catheter angiography in adults. 2016. https://www.acr.org/-/media/ACR/Files/Practice-

Parameters/CervicoCerebralCathAngio.pdf (Date of the application 15 March, 2019).

9. Ahn SS, Baker JD, Walden K, Moore WS. Which asymptomatic patients should undergo routine screening carotid duplex scan? Am J Surg 1991; 162 (2): 180-3.

10. Lawes CMM, Bennett DA, Feigin VL, Rodgers A. Blood pressure and stroke: an overview of published reviews. Stroke 2004; 35 (3): 776-85. https://pubmed.ncbi.nlm.nih.gov/15053002/

11. Rashid P, Leonardi-Bee J, Bath P. Blood pressure reduction and secondary prevention of stroke and other vascular events. Stroke 2003; $34 \quad$ (11): 2741-8. https://doi.org/10.1161/01.STR.o0ooo92488.40085.15

12. Jahromi AS, Cina CS, Liu Y, Clase CM. Sensitivity and specificity of color duplex ultrasound measurement in the estimation of internal carotid artery stenosis: A systematic review and metaanalysis. $J$ Vasc Surg 2005; 41 (6): 962-72. https://doi.org/10.1016/i.jvs.2005.02.044

13. Aizenberg DJ. Cardiovascular testing in asymptomatic patients. Med Clin North Am 2016; 100 (5): 971-9. https://doi.org/10.1016/j.mcna.2016.04.004

14. European carotid surgery trialists' collaborative group. MRC European Carotid Surgery Trial: interim results for symptomatic patients with severe (70-99\%) or with mild (0-29\%) carotid stenosis European Carotid Surgery Trialists' Collaborative Group. Lancet (London, England) 1991; 337 (8752):1235-43. https://pubmed.ncbi.nlm.nih.gov/1674060/

15. Goldstein LB, Bushnell CD, Adams RJ, et al. Guidelines for the primary prevention of stroke. Stroke 2011; 42 (2): 517-84. https://doi.org/10.1161/STR.obo13e3181fcb238

16. Brott TG, Halperin JL, Abbara S, et al. 2011 ASA/ACCF/AHA/AANN/AANS/ACR /ASNR/CNS/SAIP/SCAI/SIR/SNIS/SVM/SVS guideline on the management of patients with extracranial carotid and vertebral artery disease: executive summary. J Neurointerv Surg 2011; 3 (2): 100-30. https://doi.org/10.1161/STR.obo13e3182112cc2 
17. Ricotta JJ, Abu Rahma A, Ascher E, et al. Updated Society for Vascular Surgery guidelines for management of extracranial carotid disease. $J$ Vasc Surg 2011; 54 (3): 1-31. https://doi.org/10.1016/j.jvs.2011.07.031

18. Mayberg MR, Winn HR. Endarterectomy for asymptomatic carotid artery stenosis. Resolving the controversy. JAMA 1995; 273 (18): 1459-61. https://pubmed.ncbi.nlm.nih.gov/7723161/

19. Hobson RW, Weiss DG, Fields WS, et al. Efficacy of carotid endarterectomy for asymptomatic carotid stenosis. The Veterans Affairs Cooperative Study Group. N Engl J Med 1993; 328 (4): 221-7. https://doi.org/10.1056/NEJM199301283280401

20. Halliday AL, Mansfield A, Marro J, et al. Prevention of disabling and fatal strokes by successful carotid endarterectomy in patients without recent neurological symptoms: randomized controlled trial. Lancet 2004; 363 (9420): 1491-502. https://doi.org/10.1016/So140-6736(04)16146-1

21. Howard VJ, Meschia JF, Lal BK, et al. Carotid revascularization and medical management for asymptomatic carotid stenosis: Protocol of the CREST-2 clinical trials. Int J Stroke 2017; 12 (7): 770-8. https://doi.org/10.1177/1747493017706238

22. Eckstein HH, Reiff T, Ringleb P, et al. SPACE-2: A missed opportunity to compare carotid endarterectomy, carotid stenting, and best medical treatment in patients with asymptomatic carotid stenoses. Eur J Vasc Endovasc Surg 2016; 51 (6): 761-5. https://doi.org/10.1016/j.ejvs.2016.02.005

23. Munster AB, Franchini AJ, Qureshi MI, et al. Temporal trends in safety of carotid endarterectomy in asymptomatic patients: systematic review. Neurology 2015; 85 (4): 365-72. https://doi.org/10.1212/WNL.0000000000001781

24. Naylor AR. Time to rethink management strategies in asymptomatic carotid artery disease. Nat Rev Cardiol 2011; 9 (2): 116-24. https://doi.org/10.1038/nrcardio.2011.151

25. Drozdova LYu, Martsevich SYu, Voronina VP. Simultaneous evaluation of cardiovascular risk factors prevalence and efficacy of their correction in physicians. Assessment of their expertise in contemporary clinical guidelines. Rational Pharmacother Card 2011; 7 (2): 137-44. (In Russian).

26. Martsevich SI, Kutishenko NP, Drozdova LY, et al. USDAenhanced efficacy and safety of statin therapy in patients with liver, gallbladder, and/or biliary tract diseases: The RACURS study. Ter Arkh 2014; 86 (12): 48-52. (In Russian).

27. Shalnova SA, Balanova YuA, Konstantinov VV, et al. Arterial hypertension: Prevalence, awareness, antihypertensive pharmaceutical treatment, and treatment effectiveness in Russian Federation population. Russian Journal of Cardiology 2006; (4): 45-50. (In Russian).

28. Pujia A, Rubba P, Spencer MP. Prevalence of extracranial carotid artery disease detectable by echo-Doppler in an elderly

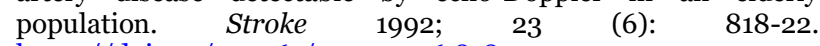
https://doi.org/10.1161/o1.str.23.6.818

29. Holloway RG, Benesch CG, Rahilly CR, Courtright CE. A systematic review of cost-effectiveness research of stroke evaluation and treatment. Stroke 1999; 30 (7): 1340-9. https://doi.org/10.1161/01.str.30.7.1340

30. Yin D, Carpenter JP. Cost-effectiveness of screening for asymptomatic carotid stenosis. J Vasc Surg 1998; 27 (2): 245-55. https://doi.org/10.1016/so741-5214(98)70355-6

31. Berger JS, Jordan CO, Lloyd-Jones D, Blumenthal RS. Screening for cardiovascular risk in asymptomatic patients. Rational Pharmacother Card 2010; 6 (3): 381-90. (In Russian). https://doi.org/10.20996/1819-6446-2010-6-3-381-390

32. Forsblad J, Gottsater A, Matzsch T, Lindgarde F. Predictors of carotid endarterectomy in middle-aged individuals. Vasc Med 2001; 6 (2): 81-5. https://pubmed.ncbi.nlm.nih.gov/11530969/

33. Jacobowitz GR, Rockman CB, Gagne PJ, et al. A model for predicting occult carotid artery stenosis: screening is justified in a selected population. J Vasc Surg 2003; 38 (4): 705-9. https://doi.org/10.1016/s0741-5214(03)00730-4

\section{Authors:}

Ivan N. Shchanitsyn - PhD, Cardiovascular Surgeon, Senior Research Scientist, Department of Innovative Projects in Neurosurgery and Vertebrology, Research Institute of Traumatology, Orthopedics and Neurosurgery, Saratov State Medical University, Saratov, Russia;

Elena Yu. Shvarts - Student, Saratov State Medical University, Saratov, Russia;

Regina A. Ishmukhametova - Student, Saratov State Medical University, Saratov, Russia;

Aina S. Vozdeeva - Student, Saratov State Medical University, Saratov, Russia 